\title{
Strike a pose! A mediação do videoclipe "Vogue" em performances do Carnaval carioca
}

\section{Strike a Pose! Mediations of "vogue" music video in Performances of Brazilian Carnival}

Simone Pereira de Sá ${ }^{1}$

Rodolfo Viana de Paulo ${ }^{2}$

Resumo: $\mathrm{O}$ artigo tem por objetivo abordar as mediações do videoclipe da canção "Vogue", de Madonna, buscando discutir o seu agenciamento de corporeidades periféricas em dois momentos: na virada para a década de 1990, quando o videoclipe se apropria e amplia a visibilidade da dança voguing, praticada pela cena cultural LGBT nova-iorquina, e duas décadas depois, quando o videoclipe é, por sua vez, uma das referências para jovens dançarinos gays nas suas apresentações em alas das escolas de samba do Carnaval carioca. Assim, interessa-nos discutir as zonas de diálogo e de tensão entre performances locais e globais, tendo como aportes teóricos a discussão sobre "cosmopolitismo estético" (REGEV, 2013) e sobre as divas pop como ícones culturais (JENNEX, 2013), entre outras referências.

Palavras-chave: Vogue; Madonna; performance; videoclipe; escolas de samba.

Abstract: The article discusses the mediations of Madonna's Music Video Vogue, seeking to discuss its agency on peripheral bodies in two moments: the first, in the 80s, when the song and music video appropriates the steps and gestures of Voguing created by the LGBT scene in New York; and the second moment, two decades later, when the music video is, in turn, one of the references for young, black and gay dancers who practice Vogue dance during their

1 Universidade Federal Fluminense (UFF). Niterói, RJ, Brasil.

https://orcid.org/0000-0002-5581-0508. E-mail: sibonei.sa@gmail.com

2 Universidade Federal Fluminense (UFF). Niterói, RJ, Brasil.

https://orcid.org/0000-0002-0557-6514. E-mail: rodolfo.viana@gmail.com 
presentations on Rio de Janeiro's samba schools in the present time. Thus, we are interested in discussing the areas of dialogue and tension between local and global performances, having as theoretical contributions the discussion on "aesthetic cosmopolitanism" (REGEV, 2013) and on pop divas as cultural icons (Jennex, 2013), among others.

Keywords: Vogue; Madonna; performance; videoclips; samba schools. 
O ano era 1990. Para Madonna, a década de 1980 se encerrava sob os holofotes do bem-sucedido álbum Like a Prayer. Em busca de uma nova canção que pudesse ser lançada como lado B do single de "Keep it Together", ela compõe "Vogue". "Strike a pose, there's nothing to it. Vogue, Vogue, Vogue".

A música se inspira na dança de mesmo nome praticada nas pistas LGBT dos clubes nova-iorquinos, onde dançarinos criaram uma série de gestos, poses e movimentos de corpo que imitam suas estrelas favoritas de Hollywood, bem como as modelos de capa da revista Vogue. E seu videoclipe, filmado em preto em branco, apresenta Madonna reproduzindo os passos e poses do vogue num cenário glamouroso, que recria a ambiência da Hollywood dos anos 1920.

Ao longo dos anos, esse clipe se tornou um ícone da obra de Madonna. ${ }^{3}$ Mas não apenas. Pois, se fizermos um corte para os anos recentes da segunda década de 2000, vamos encontrar dançarinos cariocas negros e homossexuais que utilizam passos do vogue durante suas apresentações em algumas alas das escolas de samba do Carnaval do Rio de Janeiro. E que mencionam o videoclipe de Madonna ou suas derivações em clipes de dançarinos como Yanis Marshall, ${ }^{4}$ Leiomy ${ }^{5}$ e o grupo pop Kazaky, ${ }^{6}$ que perpetuam e disseminam o vogue a partir do YouTube como uma das referências para um conjunto de poses e gestos que desenvolvem em suas rotinas coreográficas.

Com base nessas observações, nosso artigo tem por objetivo abordar as mediações do videoclipe Vogue, de Madonna, buscando discutir seu agenciamento de "corpos periféricos" em dois momentos. O primeiro,

3 Por exemplo, o videoclipe teve nove indicações para o MTV Video Music Awards de 1990 e foi incluído na $28^{\text {a }}$ posição entre os 100 melhores videoclipes listados pela revista Rolling Stone em 1993. Disponível em: https://pt.wikipedia.org/wiki/Vogue_(canção)\#cite_note-12. Acesso em: 1 ago. 2018.

4 Yanis Marshall é um dançarino e coreógrafo francês especializado em coreografias realizadas de salto alto conhecidas como stilletto. Ver vídeo disponível em: https://www.youtube.com/ watch?v=mDzx33NTg20. Acesso em: 12 ago. 2018.

5 Leiomy Maldonado é uma dançarina, instrutora, ativista e modelo trans que ganhou especial visibilidade a partir da série televisiva Pose do canal FX. Disponível em: https://en.wikipedia. org/wiki/Leiomy_Maldonado. Acesso em: 21 ago. 2018.

6 Grupo ucraniano de música pop. Ver vídeo disponível em: https://www.youtube.com/ watch?v=7Td3QW-QRwA. Acesso em: 26 jun. 2018. 
quando Madonna se apropria de elementos da cena LGBT nova-iorquina, por ocasião da criação da canção e do videoclipe de "Vogue", transformando essa dança vinda do underground numa referência para a cultura pop. O segundo momento, duas décadas depois, quando o videoclipe é, por sua vez, uma das referências para jovens dançarinos negros e gays executarem seus passos nas escolas de samba cariocas. Agenciamentos que, no caso dos dançarinos cariocas, não se filiam estritamente à cultura vogue das famosas houses - grupos culturais que desenvolveram estilos específicos de dançar o vogue desde os anos 1980 -, mas que se disseminam a partir de misturas com outros ritmos locais como o funk e o samba, caso que vamos abordar.

Ao propor a reflexão sobre o agenciamento de corpos periféricos, nosso trabalho se articula a indagações que vêm sendo desenvolvidas em nossos projetos de pesquisa sobre as formas como o imaginário e a iconografia do pop - sobretudo das divas pop - são encenados e performatizados em cenários periféricos, articulando questões de performance, corporeidades e cultura popular midiática (PEREIRA DE SÁ, 2017; VIANA DE PAULO, 2018). Assim, tomando as imagens das divas pop como "epicentros estéticos" (PEREIRA DE SÁ; SOARES, 2019) que apontam para um tipo de corporeidade que habita o mediascape da modernidade (APPADURAI, 2005), interessa-nos discutir as zonas de diálogo e de tensão que se dão em duas vias: na primeira, quando Madonna se apropria da cultura dos guetos LGBT nova-iorquinos; na segunda, quando dançarinos LGBT cariocas se apropriam do vídeo como referência para suas coreografias.

Para tanto, o trabalho se organiza em três partes. Na primeira, buscamos alguns aportes teóricos para a discussão em torno desse trinômio; na segunda, descrevemos o contexto de surgimento do videoclipe e os diálogos entre Madonna e a cena nova-iorquina dos anos 1980/1990; na terceira, discutimos as apropriações que alguns dançarinos cariocas negros e gays da ala do Maculelê, da escola de samba Acadêmicos do Salgueiro, do Rio de Janeiro, fazem do vogue no contexto dos desfiles e das apresentações das escolas de samba a partir de incursão etnográfica 
e entrevistas realizadas com dançarinos da ala. ${ }^{7}$ Trata-se, assim, de um artigo que mapeia questões e apresenta os primeiros resultados de pesquisas em andamento que serão desdobrados posteriormente em novas incursões ao campo. ${ }^{8}$

\section{Divas pop, cosmopolitismo estético e performance}

Conforme discutimos anteriormente (PEREIRA DE SÁ; SOARES, 2019), a palavra "diva" aparece na música ligada primeiramente às grandes cantoras de ópera, as célebres prima donnas, estendendo seu uso ao longo do século XX para se referir não apenas aos ícones culturais do cinema, da música e da cultura de entretenimento, mas, mais recentemente, à qualquer mulher poderosa, espetacular e glamourosa (PEREIRA DE SÁ; SOARES, 2019).

Explorando a relação entre a cultura gay e o culto das divas no ambiente da ópera, Jennex (2013) destaca os clichês, os artifícios e o exagero da representação do amor heterossexual como elementos da performance operística. ${ }^{9} \mathrm{Na}$ música pop, por sua vez, o termo se refere à linhagem de cantoras/artistas transnacionais que enfatizam o espetáculo visual, a presença cênica, a coreografia e o desenvolvimento de personagens dramáticos. Diana Ross, Madonna, Britney Spears, Rihanna, Lady Gaga e Beyoncé podem ser vistas como exemplos da mesma linhagem de mulheres que encenam formas de estar no mundo "pela

7 Um dos autores deste artigo frequentou os ensaios da ala no período entre abril e agosto de 2017. As entrevistas, por sua vez, foram realizadas com Lucas Gabriel (maio de 2017), Victor Cantuária (junho de 2017) e Vinicius Monteiro (julho de 2017).

8 Trata-se dos projetos "Cartografias do urbano na cultura musical e audiovisual: som, imagem, lugares e territorialidades em perspectiva comparada” (2014-2020), coordenado por Simone Pereira de Sá e financiado pelo edital Capes/Procad; "Estratégias de visibilidade da música pop-periférica do Brasil contemporâneo: entre o local, o transnacional e o periférico", de Simone Pereira de Sá e financiado pelo edital PQ/CNPq (bolsa de produtividade 1D); e "Na terra de malandro nós somos bandidas': a disseminação viral dos corpos que maculam as convenções do samba”, de Rodolfo R. Viana de Paulo, em desenvolvimento no doutorado do PPGCOM/ UFF sob orientação da professora Simone Pereira de Sá, também contando com auxílio da bolsa Capes e incentivo do edital do Programa de Pesquisa e Produtividade da Universidade Estácio 2019.

9 "In opera, emotions and plots are, Bronski argues, exaggerated to the point of absurdity" (JENNEX, 2013, p. 352). 
ideia de feminilidade fortalecida, consciência corporal, entretenimento e aspectos políticos relacionados a mulheres e homossexuais" (XAVIER, EVANGELISTA e SOARES, 2016, p. 96).

Em seu artigo, Jennex relaciona a imagem da diva à discussão de Rogers (1999) sobre ícones culturais, entendidos como

$[\ldots]$ aqueles objetos ou pessoas que se tornam catalisadores de fantasias e identificações para grandes públicos por sua versatilidade e abertura a diversos sentidos, permitindo assim diversas apropriações culturais e camadas de identificação cultural e multifacetada (JENNEX, 2013, p. 351).

Além disso, paradoxalmente, os ícones permitem a evocação de sentimentos de comunidade e diferença. Assim, o que dá vida e sustenta os ícones culturais - nos quais as divas estão inseridas - são as "experiências, lembranças e fantasias" dos indivíduos que os adoram (JENNEX, 2013, p. 351).

Portanto, relacionar as performances das divas ao contexto da discussão sobre a versatilidade e multivocalidade de ícones culturais nos ajuda a apreendê-las, primeiramente, a partir de sua presença como parte do imaginário pop global que Appadurai (2005, p. 35) chama de "mediascape da modernidade”, entendido por nós como o arquivo de imagens, memórias e afetos adquiridos através do aparato midiático globalizado e que atravessa distintas territorialidades e temporalidades.

A utilização da noção de performance, por sua vez, filia-se à perspectiva comunicacional e é entendida por nós como "um processo comunicativo ancorado na corporeidade e ao mesmo tempo uma experiência de sociabilidade, uma vez que supõe regras e convenções negociadas" (PEREIRA DE SÁ e HOLZBACH, 2010); também como "comportamento restaurado" (SCHECHNER, 1988). Trata-se, portanto, conforme aponta Taylor (2013), de uma episteme, uma forma de produzir conhecimento e negociar posições a partir da tangibilidade dos corpos (PEREIRA DE SÁ; SOARES, 2019). ${ }^{10}$

10 Para uma discussão da noção de performance em perspectiva comunicacional, ver Amaral, Soares e Polivanov (2018). 
Finalmente, a noção de cosmopolitismo estético (REGEV, 2013) se refere a essa dinâmica de mútua circulação e apropriação entre os ícones globais e locais definida pelo autor como uma condição cultural mais ampla que atravessa a experiência dos habitantes de diferentes países, mesmo aqueles considerados periféricos, em relação aos fluxos culturais hegemônicos. Longe de argumentos maniqueístas sobre a relação de dependência das culturas "periféricas" em relação aos centros globais, o autor discute como as singularidades culturais são articuladas (e não apagadas) nos processos globais de circulação de bens de consumo e imagens, destacando as práticas culturais de negociação entre o local e o global, que pretendemos esmiuçar a partir da análise das múltiplas mediações do videoclipe "Vogue".

\section{Vogue: poses, corporeidades mediadas e um videoclipe}

Retomando o emblemático documentário Paris is burning (1991), é possível conhecer os aspectos culturais que originam o estilo de dança e, em especial, as expressões de gênero de pessoas negras LGBT da periferia de Nova York entre as décadas de 1980 e 1990.

O filme apresenta aspectos da cultura drag, cujos integrantes, diante da falta de acesso ao glamour dos vultuosos trajes da famosa revista de moda Vogue, ironizam seu bom gosto criando o estilo de dança batizado com o mesmo nome, estilizando movimentos corporais na forma de poses que mimetizam os editoriais do mundo fashion. Abordando os concursos informais de drags queens que ocorriam nas boates underground da cidade, o documentário enfatiza a forma como as coreografias do vogue encenam, por meio do gesto dançante, um corpo que se insurge contra a sexualidade heteronormativa:

Em um ambiente sociocultural (New York, 1980) em que os heterossexuais e brancos podiam fazer tudo enquanto os gays deviam controlar como se vestiam, falavam e se portavam, a ball culture forjava espaços em que os participantes podiam ser o que quisessem, mostrar sua elegância, sedução, beleza, habilidades e conhecimentos (BERTE, 2014, p. 70). 
A força gestual, somada à invenção de uma indumentária - ou melhor, ao stealing (roubar) - reapropriada das vestimentas do mundo fashion e feita a baixo custo pelos próprios dançarinos, deixa visível como a dinâmica dos ícones da cultura pop global é agenciada localmente. Assim, a corporeidade assumida durante a dança pode emprestar a ideia de um desfile de moda, refazendo-o em uma ambiência que ora pode ser vista apenas como um solo de dança, ${ }^{11}$ ora como se fosse um enfrentamento a outro voguer dancer, nos desafios que se notabilizaram como as batalhas entre as houses. ${ }^{12}$

Nesse contexto, cabe retomar a discussão de Lepecki (2005) sobre a potência do gesto parado, o still act, no contexto da dança moderna. Segundo Lepecki (2005, p. 14), a imobilidade da pose não significa um congelamento do movimento, mas outra relação com a temporalidade do gesto, que leva o sujeito a romper com ritmos corporais preestabelecidos. Nesse sentido, trata-se de corpo que guarda informação, transmite, se atualiza, distorce e cria elementos simbólicos de acordo com o território que vivencia. Ou, como coloca Jussara Setenta (2008) em sua tese, é o corpo que é mídia de si mesmo, ou seja, um “corpomídia” que está em constante permeabilidade, que não é apenas processador, mas sim produtor de uma "relação de constante coautoria entre corpo e ambiente” (SETENTA, 2008, p. 37).

Em diálogo com essas reflexões, entendemos que os passos e poses do voguing, desenvolvidos desde os anos 1980 a partir de um complexo glossário de nomes e legendas de movimentos, ${ }^{13}$ não significam uma imitação ou reprodução irrefletida de poses "prontas" extraídas da mídia, mas sim a criação de coreografias que vão dialogar com os aspectos identitários e locais das cenas culturais que discutimos a seguir.

11 Esta é chamada de 007, conforme Victor Cantuaria explica sua posição na cena do Rio de Janeiro (VIANA DE PAULO, 2017b).

12 Cabe esclarecer que há muitos estilos para se dançar vogue, como explica a voguer dancer Raquel Pereira em vídeo disponível em: https://www.youtube.com/watch?time_ continue $=3 \& v=$ cniZbHUAlOA. Acesso em: 26 jun. 2018

13 Entre muitos outros, podemos citar os movimentos de catwalk (desfile), duckwalk (performance no chão), dips e drops (quedas), spins (giros). Cada house reivindica um modo específico de dançar cada passo. 


\section{0 videoclipe de Madonna}

Após o contato com os dançarinos de Nova York, Madonna lança, em 1990, "Vogue", uma de suas canções e videoclipes mais famosos (VOGUE, 1990a), em que convida o ouvinte a fazer uma pose - strike a pose! A canção, inspirada na cena anteriormente descrita e, sobretudo, pelos coreógrafos José e Luiz Xtravaganza, da comunidade House Ball, do Harlem, se apropria dos passos do vogue para conclamar os ouvintes à pista de dança. "It makes no difference if you're/Black or white/If you're a boy or a girl/If the music's pumping/It will give you new life/You're a superstar/Yes, that's what you are, you know", ${ }^{14}$ canta Madonna.

O videoclipe, por sua vez, conecta a cena LGBT à memória iconográfica hollywoodiana numa performance que presta homenagem às divas do cinema das décadas de 1920 e 1930. Dirigido por David Fincher e filmado em preto e branco num cenário art déco - no The Burbanks Studios, na Califórnia -, o videoclipe utiliza fotos de estrelas de Hollywood, recriando poses famosas de atrizes como Marilyn Monroe, Greta Garbo, Marlene Dietrich, Katherine Hepburn e Jean Harlow, entre outras. Referências que são sublinhadas na letra da canção, junto com atores também icônicos.

Greta Garbo and Monroe

Dietrich and DiMaggio

Marlon Brando, Jimmy Dean

On the cover of a magazine

Grace Kelly; Harlow, Jean

Picture of a beauty queen [...]

Don't just stand there, let's get to it

Strike a pose, there's nothing to it

Vogue $^{15}$

14 "Não faz diferença se você é negro ou branco/Se você é menino ou menina/Se a música está 'bombando'/Ela vai te dar vida nova/Você é um(a) superstar/Sim, isso é o que você é, você sabe" (tradução nossa).

15 "Greta Garbo e Monroe/Dietrich e DiMaggio/ Marlon Brando, Jimmy Dean/ Na capa de uma revista/Grace Kelly; Harlow, Jean/ Retratos de rainhas da beleza [...]/Não fique aí parado/ Vamos começar/Faça uma pose/Não tem segredo nenhum/Vogue” (tradução nossa). 
Cabe sublinhar a contribuição de David Fincher, cineasta e produtor que iniciou sua carreira na Industrial Light and Magic (IML) de George Lucas e que construiu reputação através de filmes como Seven - Os sete crimes capitais (1995) e Clube da Luta (1999). ${ }^{16}$ Como diretor de videoclipes, trabalhou com Madonna anteriormente em "Express Yourself" (1989) - videoclipe que, assim como "Vogue", traz referências cinematográficas que remetem à era de ouro do cinema norte-americano. Assim, com a ajuda de Fincher, Madonna envolve as referências da cultura dos guetos LGBT oitentistas com uma roupagem hollywoodiana, ampliando sua visibilidade e, ao mesmo tempo, limpando-a de suas marcas mais locais. Nesse processo, a ironia e o deboche da dança vogue "original" são atenuados e a canção incorpora uma mensagem motivacional sobre o prazer da pista de dança, enquanto os movimentos corporais abruptos e provocativos da pose gerada pelo vogue passam a vibrar com a habilidosa destreza dos bailarinos profissionais que acompanham Madonna, ganhando uma linguagem próxima da cultura pop.

Ao acionarmos a ideia de cultura pop, interessa-nos abordá-la a partir do conjunto de tensões que o termo produz. Tensões advindas do fato de que o pop se enraíza na lógica mercantil, negociando com as exigências do mercado global e acionando um conjunto de clichês, ao mesmo tempo que constrói uma estrutura de sentimentos, uma matriz de sensibilidade estética (PEREIRA DE SÁ, FERRARAZ e CARREIRO, 2015) que se conecta à discussão anterior de Regev (2013) sobre o cosmopolitismo estético e de Jennex (2013) e outros autores sobre as divas pop enquanto ícones culturais que povoam o mediascape da modernidade.

Nessa direção, para além dos binarismos, interessa-nos sublinhar a potência "pop-lítica" dessa sensibilidade "bastarda" do pop (RINCON, 2016), que pode ser vista em ação quando Madonna articula um conjunto de poses-clichês das divas hollywoodianas com a cultura dos clubes

16 Além dos citados, destacam-se na carreira de Fincher outros filmes como O curioso caso de Benjamin Button (2008), A rede social (2010), com o qual ganhou o Globo de Ouro, além do seriado de TV House of Cards, que dirigiu em 2013, ganhando o Emmy de "Melhor direção em série dramática". A lista de videoclipes que ele dirigiu também é extensa e envolve artistas como Rolling Stones, Paula Abdul, Aerosmith, entre outros. Fonte: http://www.adorocinema. com/personalidades/personalidade-15709/biografia/. Acesso em: 1 fev. 2019. 
gays de Nova York, retirando o vogue do gueto e catapultando-o para o mainstream. Nesse deslocamento, o vogue atravessa fronteiras e se globaliza, chegando também às quadras das escolas de samba do Rio de Janeiro.

\section{Do voguing dos 1980 à ala de escola de samba}

$\mathrm{Na}$ cultura do Carnaval carioca, as quadras de escola ocupam um lugar - geográfico e simbólico - central, mantendo atividades coletivas durante todo o ano. ${ }^{17}$ Logo, é comum nas escolas uma agenda de atividades gastronômicas e culturais bem diversa, tais como as feijoadas que reúnem a "comunidade", as quadrilhas em períodos juninos, os ensaios abertos da bateria, as oficinas de dança e percussão, além dos shows que cada escola promove sob a nomenclatura de "ensaio". Shows cujo formato é o de uma apresentação noturna com cobrança de entrada na qual os "puxadores de samba"18 embalam a noite com sambas-enredo de sucesso e onde números de dança de diferentes estilos podem ser exibidos ao público. É nesse contexto que, além do samba em si, passos da dança vogue e de outros estilos, tais como o funk, o stiletto, a dança afro e o sertanejo, são incorporados por alguns dançarinos que integram as apresentações.

Nossa pesquisa teve como foco os dançarinos da ala do Maculelê, da agremiação Acadêmicos do Salgueiro, ${ }^{19}$ no bairro do Andaraí, na cidade do Rio de Janeiro. Criada em 2008 pelo coreógrafo Carlinhos do Salgueiro, ${ }^{20}$ a ala, com fortes referências da estética afro, se tornou uma

17 Cavalcanti (1995) destaca a importância geográfica das quadras de escolas de samba e sua ligação com os territórios das comunidades. Contudo, observa que as redes de reciprocidade que sustentam as escolas "ultrapassam a dimensão horizontal dos bairros onde se situam", atravessando a cidade (CAVALCANTI, 1995, p. 26).

18 "Puxadores" são os cantores de sambas-enredo das escolas durante os desfiles, que ganham notoriedade nessa função, como Jamelão na Mangueira. O termo era repudiado pelo mesmo Jamelão, que se autodenominava cantor e não puxador. Contudo, é de uso consagrado e popular no mundo do samba.

19 A Acadêmicos do Salgueiro é uma das escolas mais tradicionais do grupo especial, com nove campeonatos desde sua fundação em 1953, atraindo, assim, turistas e uma enorme torcida na cidade do Rio de Janeiro.

20 "Cria" do Salgueiro, destaque e passista da escola há duas décadas, o coreógrafo mantém uma estreita relação com a agremiação. Ver: http://www.srzd.com/carnaval/rio-de-janeiro/carlinhos-salgueiro-segredo-2018/. Acesso em: 1 out. 2018. 
das atrações do desfile do Salgueiro na Marquês de Sapucaí por trazer a cada ano coreografias elaboradas e inovadoras a partir do diálogo dos passos de samba com os outros estilos mencionados. Interesse que levou Carlinhos a criar um elenco fixo com componentes dessa ala para incrementar os shows nos dias dos ensaios. Desse modo, ao lado dos outros personagens do Carnaval, tais como mestres-salas e porta-bandeiras, baianas, membros da velha guarda, percussionistas e passistas, o elenco fixo da ala do Maculelê também participa dos shows do Salgueiro, apresentando elaborados números de dança com referências afro que exigem dos dançarinos uma disciplinada rotina de ensaios semanais, dirigidos com mão de ferro pelo coreógrafo.

Nesse contexto, o que nos chama atenção ao observar a ala do Maculelê é a negociação entre as tradições arraigadas do Carnaval e as performances mais pop a partir da introdução de passos de outras danças urbanas, entre as quais se inclui o vogue. Negociação delicada entre a dimensão "do espetáculo e do samba" que acompanha a história das escolas de samba (CAVALCANTI, 1995) e que permanece como um foco de tensões por tratar das convenções do Carnaval, atravessadas por um discurso que aciona ideias de tradição, autenticidade e ancestralidade para legitimar o repúdio a inovações (TROTTA, 2011). Mas que, mesmo assim, propicia aberturas para acolher performances plurais, entre elas as que são acionadas pelos dançarinos homossexuais dessa ala. 
Figura 1: Desfile do Salgueiro, 2017. Ala do Maculelê “A morte pede passagem”.

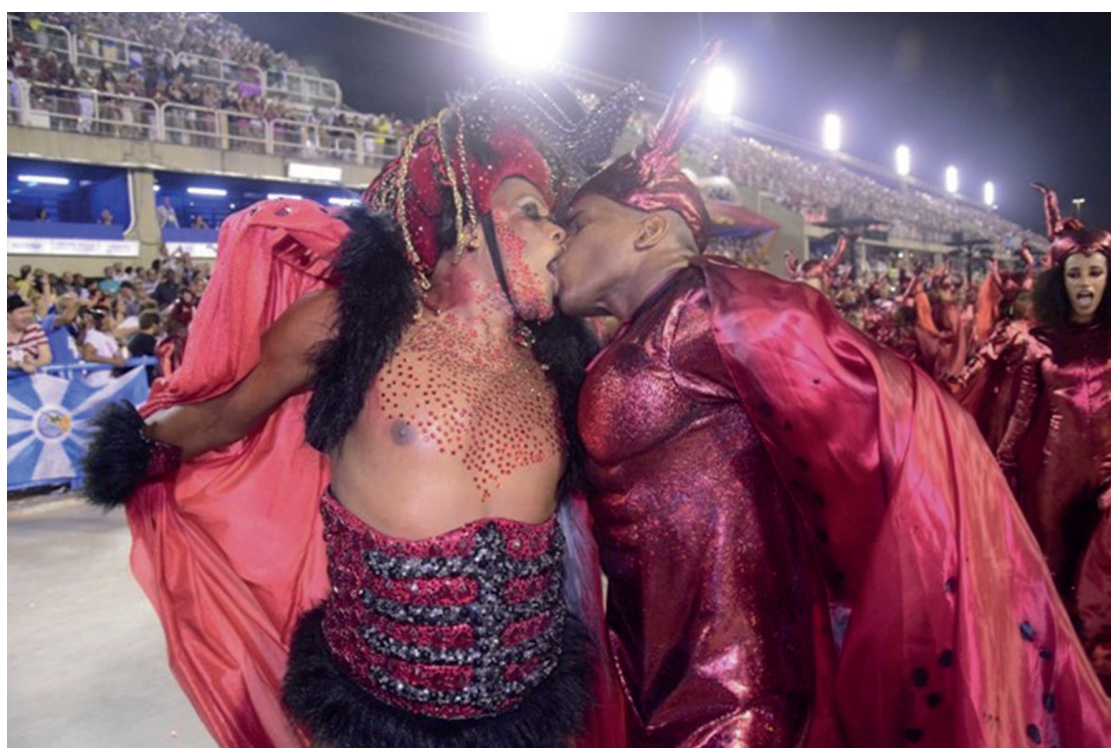

Fonte: Site O Carnavalesco.

Cabe esclarecer que a negociação que permite acolher performances que dão visibilidade a corporeidades homossexuais não significa que a ala levante bandeiras explícitas em prol de causas políticas ou de identidade de gênero, mas que amplia os espaços de diálogo com performances e referências estéticas que vão além do universo tradicional do samba. Por essa razão, as apresentações da ala dividem opiniões entre os próprios fãs dos desfiles de Carnaval. Tal como no ano de 2017 (Figura 1), quando os componentes utilizaram fantasia de espectro demoníaco, trocando beijos ao longo da Sapucaí entre pessoas do mesmo sexo, numa performance que foi reprovada por parte do público como "muito ousada". ${ }^{21}$

Nessa disputa, em que parte da comunidade do Carnaval defende um espetáculo mais tradicional e fiel aos cânones e "raízes" do samba, haveria espaço para performances "divergentes" que deem visibilidade a

21 Ver comentários da matéria “Ousadia e alegria: Carlinhos comanda ala sensual do Salgueiro". Disponível em: http://www.carnavalesco.com.br/noticia/ousadia-e-alegria-carlinhos-comanda-ala-sensual-do-salgueiro/46391. Acesso em: 9 jul. 2018. 
corporeidades LGBT, por exemplo? Haveria espaço nas escolas de samba para uma forma de sambar "mais gay"? Ou o "bom desfile", que vai emocionar a arquibancada da Sapucaí ou o ensaio das quadras, deve ser "fiel à tradição", que tende a tipificar a performance e, consequentemente, implica em não dar visibilidade a dançarinos e passistas "que dão pinta”, ou seja, que revelam, através de uma forma de dançar peculiar, a sua identidade de gênero? ${ }^{22}$

Essas questões, que suscitam discussões muito mais complexas do que este artigo nos permite explorar, acompanham a história das escolas de samba do Rio de Janeiro. Pois, ainda conforme Cavalcanti:

[...] o surgimento das escolas de samba no cenário carnavalesco possibilitou uma vasta interação entre diferentes grupos sociais, num processo que trouxe para as escolas de samba não só uma grande vitalidade, como também, talvez por isso mesmo, uma extraordinária tensão (CAVALCANTI, 1995, p. 51).

Tensão que, conforme sublinhamos, transparece em inúmeros momentos, como nos embates em torno das performances dos dançarinos da ala do Maculelê. Pois, em nossa observação da ala, constatamos o óbvio: cada componente vai com o corpo que lhe pertence. E se a forte presença da comunidade LGBT em todas as escolas pode ser observada nas mais diferentes instâncias do trabalho e do consumo em torno do Carnaval, isso não significa que as performances e corporeidades homossexuais possam circular em todas as alas de maneira não problemática.

É nesse sentido que a introdução dos passos do vogue na ala é vista pelos dançarinos homossexuais como uma possibilidade de visibilização positivada de si. Ou seja: é pelo diálogo com a cultura pop e pela frivolidade das poses do vogue nas apresentações da ala que esse corpo se dará a ver de maneira assertiva e distinta de seus pares heterossexuais.

22 Recorremos à discussão sobre performatividade de gênero (BUTLER, 2016) a fim de não essencializar as corporeidades LGBT. Não defendemos, pois, a existência da performance "típica" dos gays, mas sim de múltiplas performances "divergentes" do modelo normativo de como o "homem deve sambar" nas escolas de samba. 
Por essa via, há uma categoria nativa que permite entender melhor o lugar que os dançarinos ocupam - a ideia do close, definida como: “[...] busca de um modo de agir, uma forma de ação que arranca uma percepção estética admirável das coisas, que leva à satisfação de realizar isto ou aquilo e de mostrar" (VIANA DE PAULO, 2018, p. 97). E que aponta para esse desejo pelo admirável, o notável, sempre a partir das expressões de gênero corporificadas nas roupas, no gesto, na fala e, no caso em foco, na dança.

Figura 2: Apresentação da ala do Maculelê na quadra da Mocidade Alegre, em São Paulo (2017). À frente, Lucas Gabriel; ao fundo, à direita, Vinícius Monteiro. Foto: Alex Nunes.

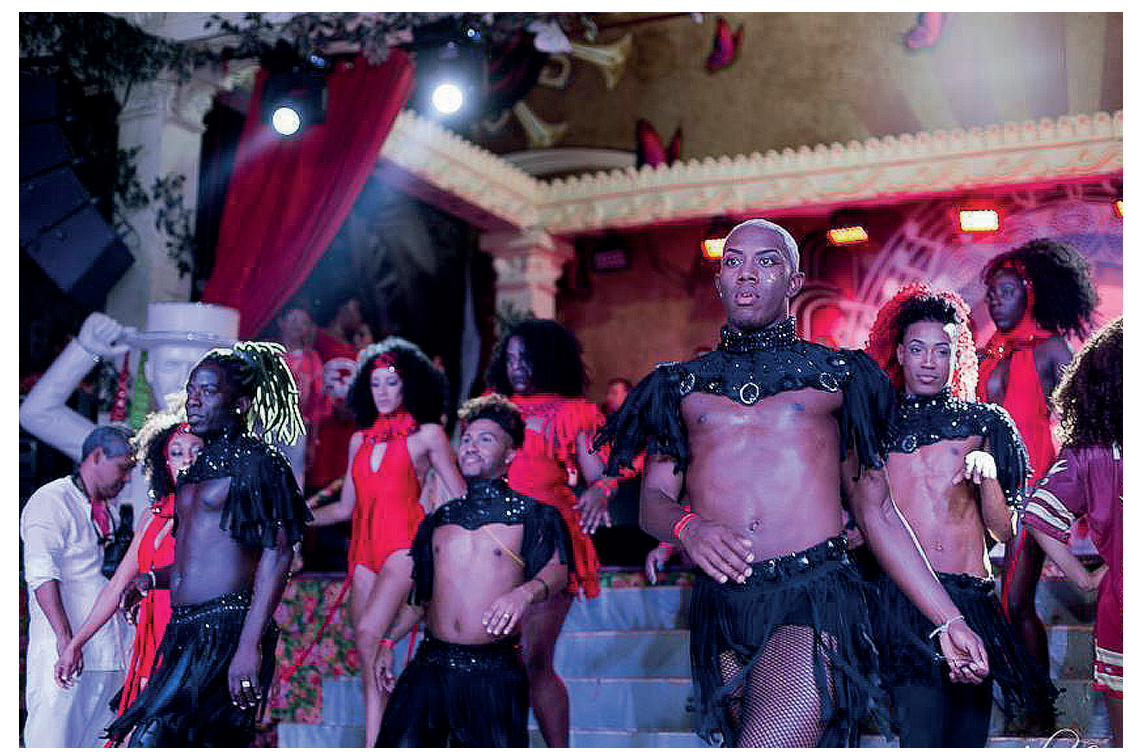

Fonte: Perfil do Facebook.

Lucas Gabriel (Figura 2), ex-dançarino da ala do Maculelê, nos explica em entrevista que a inserção do vogue nas apresentações das quadras de escola de samba ajuda a criar um clímax nas aberturas de shows em que a ala é convocada a participar. Segundo ele, ainda que a ala seja aberta a inovações, alguns recursos já se esgotaram, tal como a utilização da estética afro, abrindo-se, assim, novas oportunidades. 
Quando perguntamos por que levar o vogue para uma ala carnavalesca, Lucas Gabriel reafirma: "O vogue é close, é chamar atenção". As aberturas de shows precisam disso, é o que interessa.

Em determinadas coreografias, é isso que o povo quer ver numa quadra. Fomos [o Salgueiro] nos apresentar em São Paulo, na quadra da Vai-Vai [escola de samba paulista], o Vinícios [dançarino] entrou dando suicídio [dip], dando cambré, ${ }^{23}$ a quadra foi à loucura. Foi o auge do show (VIANA DE PAULO, 2017a).

O dançarino Vinícius Monteiro, mencionado por Gabriel, foi quem introduziu os passos de vogue na ala quando passou a integrá-la, em 2013. Sua percepção é de que seu modo próprio de dançar deve sempre misturar passos de gêneros distintos, criando para si uma assinatura, uma marca distintiva em que sejam visíveis seus trejeitos de jovem negro e gay:

[...] se eu vou sambar, eu coloco um pouco de hip-hop, ou se eu vou fazer hip-hop eu coloco um afro house, que é para diferenciar. No caso da ala de Maculelê, eu coloco vogue em meus passos que eu aprendi pelos vídeos da Leiomy, lá dos Estados Unidos, e também por alguns amigos que dançam vogue. Só que aqui não tem muita batalha de vogue [para eu ir]. [...] O Maculelê é uma ala afro, mas quando tem os momentos de solo, eu faço a minha parte jogando vogue. Quando eu fiz a primeira vez, conquistou o público [na quadra] e agora eu faço sempre pra levantar o "griteiro" do povo mesmo (VIANA DE PAULO, 2017c).

Nesse sentido, os vídeos acessados através do YouTube assumem lugar importante no próprio estudo e no aprendizado da dança, tornando-se um elo que cria pontes e trocas de saberes acerca do corpo dançante em contextos locais e globais (PEREIRA DE SÁ e SOARES, 2019). No caso do vogue, o clipe de Madonna é uma referência sempre citada dessa corporeidade "popular mainstream" (RINCON, 2016) - não só o videoclipe oficial da canção, mas também a performance ao vivo da cantora no MTV Video Music Awards (VOGUE, 1990b), seis meses

23 Ultraenvergamento da coluna para trás com admirável destreza, recurso comum ao vogue. 
depois do lançamento do clipe, em que Madonna encena uma antiga corte dançando a música. Naquele segundo momento, distanciando-se da gestualidade apresentada no próprio clipe, Madonna se vira para seus bailarinos e diz "Pose!", permitindo que cada um apresente seu gesto parado. Nessa apresentação, há formas mais populares e conhecidas do vogue que podemos identificar em várias apresentações dos dançarinos cariocas.

Já as performances atuais de dançarinos populares na rede, como Leiomy - voguer citado como inspiração de Vinícius Monteiro -, que utiliza samples próprios, alguns com menção a Madonna, nos fazem observar o vogue a partir de sua derivações e atualizações. Assim, a mediação desses vídeos permite aos dançarinos autodidatas o aprendizado dos passos e o entendimento dos gestos que fazem mais sucesso nas apresentações ao vivo - gestualidades "que dão mais close" e que deixam o público eufórico.

Vinícius Monteiro explica que, a partir dos vídeos, ele seleciona - ou “rouba" (stealing, no jargão dos voguers) - aquilo que julga conveniente ao espetáculo carnavalesco, misturando outras referências. Também Victor Cantuaria entende como "natural" a fusão do ritmo com outras referências culturais, de forma tangente e fora da ambiência da cultura dos voguers.

Desse modo, o relato desses dançarinos nos permite argumentar que a presença do vogue nas quadras de escola de samba se dá através de uma apropriação transversal e refletida dos gestos que produzem o efeito catártico e espetacular de arrancar o "griteiro" do público a partir dos closes de seus dançarinos, adaptando-os para nossos territórios locais. Logo, o vogue possibilita aos dançarinos um lugar de pertencimento a partir da cultura bastarda do pop (RINCON, 2016). Lugar cosmopolita e que permite vislumbres de outras formas de "cair no samba" agenciadas por corpos negros, homossexuais e periféricos. 


\section{Considerações finais}

$\mathrm{Na}$ presente discussão, tomamos o videoclipe de "Vogue", canção de Madonna, como um artefato cultural que aciona e media um conjunto de poses e gestos de corpos periféricos em dois momentos distintos: o primeiro em 1990, quando a cantora se apropria da dança vogue, criada nos clubes LGBT de Nova York, e a transforma numa referência para a cultura pop; o segundo na atualidade, quando dançarinos gays da ala do Maculelê, da escola de samba Acadêmicos do Salgueiro, mesclam passos e gestos do vogue com o samba a fim de demarcar suas identidades como dançarinos homossexuais negros no contexto do que eles chamam de "dar um close" ou "causar". Assim, os passos do vogue são utilizados para sublinhar o clímax das apresentações, intensificando o espetáculo visual que faz parte dos desfiles das escolas de samba a partir de um gesto dramático e icônico que nos remete ao universo das divas pop.

Um segundo aspecto a destacar é que a utilização do vogue - mesclado com outros passos, como o stilleto ou o funk - parece ter por objetivo "modernizar" a apresentação da ala, que se pauta por uma estética afro de forte impacto estético, mas avaliada por esses dançarinos como já excessivamente explorada e, portanto, esgotada. Assim, a corporeidade das divas acionada no videoclipe é um caminho para a construção de uma sensibilidade mais pop no mundo do Carnaval, confirmando o desejo de cosmopolitismo estético desses componentes.

Como terceira questão, destaca-se o papel dos videoclipes como mediadores para a construção dessa performance. E se o videoclipe "Vogue", de Madonna, é o epicentro estético fundamental, também nos interessa destacar as suas derivações, seja em outras apresentações da própria cantora, tal como durante o MTV Video Music Awards, seja nos vídeos de outros dançarinos, como Yanis Marshall, Leiomy e o grupo Kazaky, citados pelos nossos entrevistados como referências importantes para a criação de suas coreografias. Queremos, assim, pensar no videoclipe de Madonna como mediador de um conjunto de imagens, gestos, poses e movimentos que se espraiam e são apropriados em inúmeras direções, entre elas a performance dos dançarinos da ala do Maculelê no Salgueiro. 
Finalmente, como quarta questão, interessa-nos enfatizar o aspecto bastardo (RINCON, 2016) que une a cultura pop à cultura do Carnaval. Pois, conforme observa Cavalcanti (1995, p. 213):

[...] como todas as formas rituais e dramáticas, o desfile expressa a consciência profunda do aqui e do agora, para fazer é preciso refazer sempre; e como ele pertence ao carnaval, o seu aqui e agora é a celebração alegre dos limites: viva o corpo, a matéria, o pecado e a finitude.

E não é também disso que trata a cultura pop e, em especial, a canção "Vogue" quando conclama seus ouvintes à pista de dança? "When all else fails and you long to be/Something better than you are today/I know a place where you can get away/It's called a dance floor, and here's what it's for, so/Come on, Vogue". ${ }^{24}$ Essa é uma articulação importante, que aponta para as potências do presenteísmo, do hedonismo, do humor e da joie de vivre como formas de expressão da cultura popular.

Através dessas questões, que apontam para desdobramentos previstos em futuros trabalhos, discutimos alguns rastros da trajetória desse videoclipe e sua inscrição no imaginário e no arquivo de poses, gestos e corporeidades que constituem a sensibilidade pop a partir de múltiplos caminhos, desvios, corporeidades e territorialidades.

\section{Referências}

AMARAL, A.; SOARES, T.; POLIVANOV, B. Disputas sobre performance nos estudos de comunicação: desafios teóricos, derivas metodológicas. Intercom - Revista Brasileira de Ciências da Comunicação, São Paulo, v. 41, n. 1, p. 63-79, jan.-abr. 2018.

APPADURAI, A. Modernity at large: cultural dimensions of globalization. Minnesota: University of Minnesota Press, 2005.

BERTE, O. Vogue: dança a partir de relações corpo-imagem. Revista Dança, Salvador, v. 3, n. 2, p. 69-80, jul.-dez. 2014.

24 "Quando tudo fracassar e você desejar ser/Algo melhor do que você é hoje/Eu conheço um lugar para onde você pode fugir/Se chama pista de dança e é para isso que ela serve, então/ Vamos lá, Vogue" (tradução nossa) 
BUTLER, J. Problemas de gênero: feminismo e subversão da identidade. Rio de Janeiro: Civilização Brasileira, 2016.

CAVALCANTI, M. L. Carnaval carioca: dos bastidores ao desfile. Rio de Janeiro: UFRJ: Funarte, 1995.

JENNEX, C. Diva worship and the sonic search for queer utopia. Popular Music and Society, v. 36, n. 3, p. 343-359, 2013.

LATOUR, B. Reagregando o social: uma introdução à teoria do ator-rede. Salvador: EdUFBA; Bauru: Edusc, 2012.

LEPECKI, A. Desfazendo a fantasia do sujeito (dançante): 'Still acts' em The Last Performance de Jérôme Bell. In: SOTER, S.; PEREIRA, R. (Orgs.). Lições da dança 5. Rio de Janeiro: UniverCidade, 2005.

PARIS IS BURNING. Direção, roteiro e produção: Jennie Livingston. EUA, 1991. Documentário (78 min).

PEREIRA DE SÁ, S. Cultura digital, videoclipes e a consolidação da Rede de Música Brasileira Pop Periférica. In: ENCONTRO ANUAL DA COMPÓS, XXVI, 2017, São Paulo. Anais... São Paulo, 2017.

PEREIRA DE SÁ, S.; FERRARAZ, R.; CARREIRO, R. Apresentação. In:

(Orgs.). Cultura Pop. Livro Compós 2015. Salvador: EdUFBA, 2015.

PEREIRA DE SÁ, S.; HOLZBACH, A. \#U2youtube e a performance mediada por computador. Revista Galáxia, São Paulo, n. 20, p. 146-160, dez. 2010.

PEREIRA DE SÁ, S.; SOARES, T. Beyonce's performance in Brazilian bodies: the role of Beyoncé on the construction of "pop diva" in funk carioca and tecnobrega. In: BAADE, C. et al. Making Lemonade: finding art, activism, and community with Beyoncé in troubled times. [s. 1.], 2019. No prelo.

REGEV, M. Pop-rock music: aesthetic cosmopolitanism in late modernity. Cambridge: Polity Press, 2013.

RINCON, O. O popular na comunicação: culturas bastardas e cidadanias celebrities. Revista Eco-Pós. Rio de Janeiro, v.19, n. 3, set/dez. 2016.

ROGERS, M. Barbie culture. Londres: Sage, 1999.

SCHECHNER, R. Performance theory. Londres: Nova York: Routledge, 1988.

SETENTA, J. O fazer-dizer do corpo: dança e performatividade. Salvador: EdUFBA, 2008.

TAYLOR, D. O arquivo e o repertório. Belo Horizonte: UFMG, 2013.

TROTTA, F. O samba e suas fronteiras. Rio de Janeiro: UFRJ, 2011.

VIANA DE PAULO, R. O imundo, o funk e as bixas-pretas: imagens, performances e as poses no portrait fotográfico. 2018. Dissertação (mestrado) - Universidade Federal do Rio de Janeiro, Escola de Comunicação, Programa de Pós-graduação em Artes da Cena, Rio de Janeiro, 2018.

. Entrevista com Lucas Gabriel. Rio de Janeiro, maio 2017a.

. Entrevista com Victor Cantuaria. Rio de Janeiro, jun. 2017b.

. Entrevista com Vinicius Monteiro. Rio de Janeiro, jul. 2017c.

Comun. mídia Consumo, SÃo PaUlo, v. 16, N. 46, P. 376-396, Mai./AGo. 2019 
396 STRIKE A POSE!

VOGUE. Direção: David Fincher. Performance: Madonna. EUA, 1990a. Videoclipe (293 s). Disponível em: https://www.youtube.com/watch?v=GuJQSAiODqI. Acesso em: jul. 2019.

VOGUE. Performance: Madonna. EUA: MTV Video Music Awards, 1990b. Disponível em: https://www.youtube.com/watch?v=lTaXtWWR16A. Acesso em: jul. 2019.

XAVIER, L.; EVANGELISTA, S.; SOARES, T. Performatividade de gênero na música popular periférica. In: PEREIRA DE SÁ, S.; POLIVANOV, B.; EVANGELISTA, S. (Orgs). Música, som e cultura digital: perspectivas comunicacionais brasileiras. Rio de Janeiro: E-papers, 2016.

\section{Sobre os autores}

Simone Pereira de Sá - Professora titular do Departamento de Estudos Culturais e Mídia e do Programa de Pós-graduação em Comunicação (PPGCOM) da Universidade Federal Fluminense (UFF). Bolsista de produtividade 1D do CNPq. Coordenadora do Laboratório de Pesquisas em Culturas e Tecnologias da Comunicação (LabCult).

Rodolfo Viana de Paulo - Doutorando do PPGCOM/UFF e pesquisador do LabCult. Graduado em Publicidade, fotógrafo, docente e membro integrante do Programa de Pesquisa e Produtividade da Universidade Estácio de Sá.

Data de submissão: 24/10/2018

Data de aceite: 24/02/2019 